\title{
Foundations for the future: preparing tomorrow's medical educators today
}

\author{
Jennifer A Heathcote, ${ }^{1}$ Elizabeth Nyholm ${ }^{2}$
}

\begin{abstract}
${ }^{1}$ Associate Specialist and General Training Programme Director, East Cheshire NHS Trust, East Cheshire Community Sexual Health Clinic, Macclesfield, UK ${ }^{2}$ GP Principal and GP Trainer, Omnia Medical Practice, Birmingham, UK
\end{abstract}

\section{Correspondence to} Dr Jennifer Heathcote, East Cheshire NHS Trust, East Cheshire Community Sexual Health Clinic, New Alderley Building, Macclesfield District General Hospital, Victoria Road, Macclesfield SK10 3BL, UK; j.heathcote@nhs.net

Received 6 September 2012 Revised 14 October 2012 Accepted 15 October 2012

To cite: Heathcote JA, Nyholm E. Journal of Family Planning and Reproductive Health Care 2013, 39 , 14-16.

\section{BACKGROUND}

Good teachers have a major influence on the quality and safety of medical care delivered to patients. As the area of sexual and reproductive health care (SRH) has evolved there has always been a strong commitment to supporting the development of sexual health teachers. The first guidelines were produced in 1977 at the request of the Joint Committee for Contraception, with a revision in $1985,{ }^{1}$ and further revisions in 1994 and 2006 following the establishment of the Faculty of Family Planning and Reproductive Health Care (now the Faculty of Sexual and Reproductive Healthcare). Family Planning Instructing Doctors, now termed 'Faculty Trainers', have been dedicated to the training of clinicians and have recently undertaken the delivery of the new Diploma of the Faculty of Sexual and Reproductive Healthcare (DFSRH) programme with enthusiasm. An independent evaluation of the DFSRH by Professor Ed Peile ${ }^{2}$ commended the trainers' strong ethos of striving for excellence.

Medical education research is advancing rapidly, rising to the challenge of ensuring that clinicians have the knowledge and skills to meet the health care needs of modern society. Recognition that sexual health clinicians need to be able to demonstrate reflective practice and other competencies has supported a revision of the Letter of Competence in Medical Education (LoC MEd) over the last year, resulting in the establishment of a formal university-accredited Postgraduate Award in Medical Education that aims to meet the needs of sexual health teachers.

\section{SETTING STANDARDS FOR MEDICAL TEACHERS}

General Medical Council (GMC) guidance has firmly stated the importance of 'professionalising' medical teachers: "If you are involved in teaching you must develop the skills, attitudes and practices of a competent teacher".

In 2009, the Academy of Medical Educators published the Professional Standards Framework, updated in 2012, ${ }^{4}$ which defines standards for the formal validation and recognition of medical educators. These provide a robust mechanism to inform continuing professional development, appraisal and revalidation of doctors who are currently trainers as well as the training pathways for the trainers of the future. The professional standards are defined in five domains:

1. Design and planning of learning activities

2. Teaching and supporting learners

3. Assessment and feedback to learners

4. Educational research and evidence-based practice

5. Educational management and leadership.

The GMC (and previously the Postgraduate Medical Education Training Board before they were merged) has for some time set standards for general practice (GP) trainers and how they should be trained. The government report entitled A High Quality Workforce in 2008 included a commitment that the Department of Health would ensure "that educational supervisors in secondary care undergo mandatory training and review of their performance for this role (as currently exists in primary care)". 5 The GMC Education Strategy $2011-2013^{6}$ is looking at "developing and implementing an approvals framework for all trainers of undergraduate and postgraduate learners, building on the process already in place for selecting, training and appraising GP trainers". In 2011, Medical Education England set up the Shape of Training Review ${ }^{7}$ to reform postgraduate medical education and training throughout the UK. 
Medical education differs from most other higher education since patient involvement is explicit; direct patient input into the teaching, feedback and assessment of trainees must be balanced with the provision of appropriate clinical care.

\section{DEVELOPMENT OF A JOINTLY BADGED PGA MED ED (SRH) WITH KEELE UNIVERSITY}

With these initiatives in mind, the General Training Committee of the FSRH undertook to review the route for gaining recognition as a Faculty Trainer. This decision took into account concern that new methods of assessment in the DFSRH presented different teaching challenges, with the likelihood that some DFSRH candidates would fail to achieve the required competencies. In addition, this provided an opportunity to develop a framework for ongoing development of educational knowledge and skills for established teachers, recognising the importance of a professional approach to medical teaching. ${ }^{8}$

There are currently two routes into 'Registered Trainer' status. Approved GP Trainers who have already undertaken appropriate 'teacher training' will continue to be recognised as Faculty Trainers (whilst they are active GP Trainers), after they have demonstrated appropriate knowledge and activity in the sexual health field. Doctors with the LoC MEd are also recognised as Faculty Registered Trainers, as will be those who are currently on the LoC MEd training pathway. Clinicians without this background will now follow a new training programme. The FSRH has entered into a collaborative partnership with Keele University Medical School to design a bespoke programme for SRH trainers in line with the Professional Standards Framework, jointly badged by the FSRH and Keele University. A new Postgraduate Award in Medical Education in Sexual and Reproductive Healthcare, the PGA Med Ed (SRH), with university accreditation carrying 30 Credit Accumulation and Transfer Scheme (CATS) points, is now established. It comprises modified Modules 1 and 2 of the Keele Masters in Medical Education programme.

The course is designed to be relevant to those who start with little experience of formal teaching, as well as to individuals who already teach and are looking for an accredited academic qualification that refers to the national professional standards. It also provides an opportunity for those with a specific interest in medical education to progress further in this field to Masters level.

The FSRH is committed to strengthening the positive working arrangements with others who have an interest in high-quality SRH delivery, and from its inception this award has been embraced by SRH practitioners from general practice and genitourinary medicine as well as community SRH services, and by nurses as well as doctors. Students are required to meet Keele postgraduate entry requirements and those wishing to become Faculty Trainers also need to demonstrate that they are actively working in SRH.

The training programme consists of some preliminary reading and consideration of the students' own preferred learning styles prior to an intensive 2-day residential course. The majority of the teaching on this course is undertaken in small groups; this provides an introduction to medical education and delivers the Keele Masters modules on teaching methods and theories of learning. Teaching is skills and knowledge based, and the exercises on the course are designed to cover both. Emphasis is placed on the value of the students reflecting on their own experiences as learners and teachers to inform future teaching.

A significant component of the PGA takes place after the residential course when students are required to compile an educational portfolio related to their teaching activities with reference to the five domains in the professional standards. This includes planning and delivering teaching activities in the scenarios typically seen in SRH clinics and surgeries. Students are observed whilst undertaking two teaching activities and then relate their experiences to current educational theory in a 3000 word assignment. The portfolio and this essay must be completed at Masters level in order to achieve the PGA.

Students who wish to become Faculty Registered Trainers, either now or in the future, are required to include in their portfolio evidence of teaching in four areas relevant to Faculty training: teaching a practical skill [as required for Faculty Letters of Competence in Subdermal Implants (LoC SDI) and Intrauterine Techniques (LoC IUT)]; facilitating a small group (such as the 'Course of 5' component of the DFSRH); undertaking an Assessment of Clinical Practice (ACP) following observation of a trainee during a clinical consultation; and a Reflection and Discussion of Clinical Practice (RDCP) in which the teaching is focused on a clinical scenario that the trainee has undertaken.

Currently (for reasons of Faculty statute) nurses can only be recognised as primary trainers for the LoC SDI, although they are actively involved in delivering and teaching sexual health care across the UK. It is hoped that the majority of applicants will choose to complete all the components of the portfolio so that should it become possible in the future, this training will be recognised.

\section{ONGOING PERSONAL DEVELOPMENT AS A MEDICAL TEACHER IN SEXUAL HEALTH}

The PGA Med Ed (SRH) has now replaced the LoC MEd as the Faculty 'teaching qualification' for new teachers and aims to produce a generation of doctors and nurses for whom reflective practice is integral to their personal and teaching activity. It gives such teachers the opportunity to progress their interest in medical education should they so wish and also provides a firm foundation for their continuing personal 
development. The collaboration is an important step forward and provides the opportunity to ensure that the teaching programme adapts rapidly to change with the support of Keele University Department of Medical Education. In addition, the FSRH and Keele University are in a position to develop joint programmes for SRH teachers, both LoC MedEd and PGA holders, to maintain and develop their interest and knowledge in medical education. The Faculty has recognised the importance and value of 'professionalising' its medical teachers and should be justifiably proud of this new collaborative venture.

Acknowledgements The authors would like to acknowledge the encouragement and expertise of Kay Mohanna and Charlotte Hart from the Masters in Medical Education programme at Keele University, and their support during the development of the PGA MedEd (SRH).

Funding None.

Competing interests None.

Provenance and peer review Not commissioned; externally peer reviewed.

\section{REFERENCES}

1 Cardy G, Skrine R. Training of Instructing Doctors in Family Planning - JCC Guidelines. London, UK: Joint Committee on Contraception, 1985.

2 Peile E. The Independent Evaluation of the Diploma of the Faculty of Sexual Healthcare (DFSRH) and the 'Letter of Competence' training programmes - Recommendations. 2012. http://www.fsrh.org/pdfs/DFSRH_EvaluationRecommendations. pdf [accessed 14 October 2012].

3 General Medical Council. Good Medical Practice 2006.http:// www.gmc-uk.org/guidance/good_medical_practice.asp [accessed 14 October 2012].

4 Academy of Medical Educators. Professional Development Standards. London, UK: Academy of Medical Educators, 2009.

5 Department of Health. A High Quality Workforce: NHS Next Stage Review. London, UK: Department of Health, 2008.

6 General Medical Council. GMC Education Strategy 20112013. Shaping the Future of Medical Education and Training. http://www.gmc-uk.org/Education_Strategy_2011_2013. pdf_36672939.pdf [accessed 14 October 2012].

7 General Medical Council. http://www.shapeoftraining.co.uk [accessed 14 October 2012].

8 McLean M. How to professionalise your practice as a health professions educator. Med Teach 2010;32:953-955.

\section{Quality Training in SRH Project - Nurse Training}

In response to the Peile Report on training, FSRH Council have approved funding to develop a training programme in SRH (including LARC) and qualification for nurses. This work will be carried out as part of the Quality Training in SRH project which is implementing changes to the diploma and LoC training for doctors. FSRH Council will receive regular reviews of this work and the final recommendations for the content and name of the nursing programme are expected to be received by Council in approximately 12 months. Interested individuals should refer to the FSRH website (http://www.fsrh.org/) for the latest information about this new SRH training programme for nurses.

\section{FACULTY OF SEXUAL \& REPRODUCTIVE HEALTHCARE MEMBERSHIP EXAMINATION}

The Membership Examination (MFSRH) consists of:
Part 1 Multiple Choice Question paper (MCO)
The London-based examination is held annually in April and October. Applications for the 19 April 2013 examination must be received
by $\mathbf{3}$ January $\mathbf{2 0 1 3}$ and for the $\mathbf{1 8}$ October $\mathbf{2 0 1 3}$ examination must be received by $\mathbf{1}$ July $\mathbf{2 0 1 3}$. The syllabus for the Part 1 is on the
Faculty website.
Evidence Based Commentary (EBC)
Candidates can view the released topic and candidate guidance notes for EBC on the Faculty website. There is an absolute deadline
of $\mathbf{3 1}$ August $\mathbf{2 0 1 3}$ to submit the EBC on this topic.
Part $\mathbf{2}$ Examination
This all-day examination is held annually in June in Liverpool.
Applications for the MFSRH Part 2 held on $\mathbf{1 3}$ June 2013 must be received by $\mathbf{3}$ January $\mathbf{2 0 1 3}$. Further information and the Part 2
Syllabus are on the Faculty website. The qualification is subject to re-certification every 5 years.
For the current MFSRH Examination Regulations, information on all components of the MFSRH examination and application forms,
please visit the Faculty of Sexual and Reproductive Healthcare website: www.fsrh.org (Examinations and Membership
Examination Information) or e-mail Denise Pickford: denise@ @fsrh.org.

